\title{
An agent based routing search methodology for improving QoS in MANET
}

\author{
Una metodología de búsqueda de enrutamiento basada en agentes \\ para mejorar la QoS en MANET
}

Amit Kumar Bairwa $^{1 *} \quad$ Sandeep Joshi ${ }^{1}$

Recibido 15 de julio de 2020, aceptado 1 de septiembre de 2020

Received: July 15, 2020 Accepted: September 1, 2020

\begin{abstract}
The routing performance of the In Mobile Ad-hoc Networks (MANETs) depends on the individual nodes that represent the network. In this paper, a new protocol based on self-monitoring (agent-based) and following the Ad Hoc on Demand Distance Vector (AODV) Routing Algorithm is presented. This protocol may be called Agent-Based Ad Hoc on Demand Distance Vector Routing Algorithm (AB-AODV) Protocol for MANETs. The main objective of the proposed method is to manage trusted information locally with minimal overhead in terms of extra messages and time delay. This objective is achieved through installing in each participating node in the network a multi-agent system. Multi-agent system consists of two types of agents: monitoring agent and routing agent. A new mathematical and more practical objective model for measuring the trust value is introduced. This model is weighted by both the number and size of routed packets to react to the selective forwarding behavior of a node. The performance evaluation via simulation using NS-3 shows that the proposed protocol is better than standard AODV. The simulation is done under a variety of environmental conditions such as the number of malicious nodes, host density, and movement rates.
\end{abstract}

Keywords: MANET, Routing, Agent based System, AODV, AB-AODV, Trust.

\section{RESUMEN}

El rendimiento de enrutamiento de las redes ad-hoc en dispositivos móviles (MANET) depende de los nodos individuales que representan la red. En este documento, se presenta un nuevo protocolo basado en el autocontrol (basado en el agente) y siguiendo el algoritmo de enrutamiento Ad Hoc On Demand Distance Vector (AODV). Este protocolo se puede denominar Protocolo de algoritmo de enrutamiento vectorial de distancia a demanda basado en agente a demanda (AB-AODV) para MANET. El objetivo principal del método propuesto es administrar la información confiable localmente con una sobrecarga mínima en términos de mensajes adicionales y retraso de tiempo. Este objetivo se logra mediante la instalación en cada nodo de la red de un sistema de múltiples agentes. El sistema de múltiples agentes consta de dos tipos de agentes: agente de supervisión y agente de enrutamiento. Se presenta un nuevo modelo objetivo matemático y más práctico para medir el valor de confianza. Este modelo está ponderado tanto por el número como por el tamaño de los paquetes enrutados para reaccionar el comportamiento de reenvío selectivo de un nodo. La evaluación del rendimiento mediante simulación con NS-3 muestra que el protocolo propuesto es mejor que el AODV estándar. La simulación se realiza bajo una variedad de condiciones ambientales, como la cantidad de nodos maliciosos, la densidad del host y las velocidades de movimiento.

Palabras clave: MANET, enrutamiento, sistema basado en agente, AODV, AB-AODV, Trust.

\footnotetext{
1 Manipal University Jaipur 1. Department of Computer Science and Engineering. Jaipur, India. E-mail: amitbairwa@gmail.com

* Autor de correspondencia: amitbairwa@gmail.com
} 


\section{INTRODUCTION}

MANET is a communication paradigm, which does not require a fixed infrastructure; they rely on wireless terminals for routing and transport services [1]. Nodes rely on each other to keep the network connected and to move information. The act of moving information from source node to destination node is called Routing. The routing concept basically involves two steps [2-3]. First, determine the optimal routing path and then transfer the information packets through the network. Routing protocols use several metrics to calculate the best path for routing the packet to its destination [4-6]. These metrics are a standard measurement that could be, for example, number of hops, which is used by a routing algorithm to determine the optimal path for the packet to its destination. Routing is mainly classified into static routing and dynamic routing. Static routing maintains a routing table [7-9]. Dynamic routing refers to the routing strategy that is being learned by an interior and exterior routing protocol.

\section{PROBLEM STATEMENT}

The problem with AODV is its single path selection, with a reactive approach that claims to be best at a particular instant of time, but topology is dynamic. Hence it may be changed and the network may have a better route but AODV does not check for it and continue, to the already selected path another scenario can be if any node moves away from the established path, between source to destination. Then route error comes and source has to broadcast the route request to its neighbor hence re-route discovery that increases control overhead, network latency and decreases the overall throughput of the network. The occurrence of re-routing nodes could disrupt the routing operation in MANETs. To overcome this behavior, the integrity of the network nodes should be considered in the route selection process combined with the hop count. That is the reason the concept of mobile agents in AODV is used, also called AB-AODV.

\section{METHODOLOGY}

In the proposed algorithm, any path from the source node to the destination node is a feasible solution. The optimal solution is the shortest one. At the beginning a random population of paths is generated which represents feasible or unfeasible solutions. Unfeasible solutions are paths that do not end at the destination. A prey hunting corresponds to any possible solution to the optimization problem. Thus each prey represents a path which in tum consists of a sequence of positive integers that represent the IDs of nodes through which a routing path passes with the source node followed by intermediate nodes (via nodes), and the last node indicating the destination, which is the goal. The total grey wolf count is equal to the number of nodes.

\section{PROPOSED METHODOLOGY}

This agent-based Ad Hoc On-demand Distance vector routing (AB-AODV) is an improved $A O D V$ routing protocol based on mobile agents. In ABAODV mobile agents work on the method of indirect coordination between agents, based on the footprint left in the environment by a subsequent action. Mobile agent updates routing information as well as the routing table information left by other mobile agents. Using this information, mobile agents are able to get the routing information about the mobile nodes it has not visited yet. Each agent is considered free to all other agents in the context of its code and data. An agent can move freely in the entire network. Due to the small size of the mobile agent, transmission overhead is very low. Agents communicate with other agents indirectly by mobile routing table in order to _nd out the shortest best route. As an agent helps to _nd out the best possible route between mobile nodes so if any time any agent moves to another location. Whenever a node is out of the range of other nodes then through an agent, a node can switch from the current node to the better route node. Therefore route latency can be minimized by an agent because agents save the time that consumed in the discovery of route again else in AODV whenever RERR (route error) comes it stars from the initial stage and again broadcast the RREQ (route request) packet to its one-hop neighbour nodes and repeats the whole route discovery process. By agent, AB-AODV avoids the unnecessary route discovery process by searching the alternative paths and updating these paths into the routing table of mobile nodes. Agents not only minimize the routing overhead and network delay but also improve the overall throughput of the network. 


\section{MOBILE AGENT}

Mobile Agents are simple packets that carry the data and search into the network for the available routes. Agents leave the knowledge acquired through study of the network behind the nodes that they travel to, so that other agents can use this information. As in computer networks there are various devices that are connected to the networks where mobile devices. Mobile Agents help to accumulate and distribute connectivity information for a dynamic wireless network. Topology of the mobile network is dynamic in nature because the connection between mobile nodes is established and destroyed when nodes move in the ad hoc manner. Sometimes nodes are in and out of range of each other. The mobile agent stores the past movement where it has been. When a node receives information from a mobile agent and updates its routing table with best available routes. The routing agents communicate indirectly to each other by writing the information to the routing table of mobile nodes but do not read information from the mobile nodes. When an agent comes to such a node it updates the node's routing information by its(agent) collective information as well as it reads routing information from the local routing table that builds as per the routing information collected by other agents. Hence by the help of the local routing table of each mobile node, agents can communicate with each other indirectly and help to determine the best possible routes to the mobile node.

\section{DETERMINATION OF AVERAGE NUMBER OF MANET}

In MANET that consists $\mathrm{N}$ number of mobile nodes, if a node is able to create a new mobile agent after every $\mathrm{S}$ seconds with a determinate lifetime of $\mathrm{T}$ seconds, then after a relatively long period in comparison to the agents lifetime, the average number of agents $(\mathrm{A})$ is

$$
\mathrm{A}=\mathrm{NT}_{\mathrm{E}} / \mathrm{S}
$$

where,

A $=$ average number of mobile agent

$\mathrm{N}$ = number of mobile nodes

$\mathrm{T}_{\mathrm{E}}=$ expiry time of a mobile agent

$\mathrm{S}=$ time interval to create a new agent

\section{EVALUATION OF FITNESS FUNCTION}

The fitness function $F(x)$ is defined as follows:

$$
\mathrm{F}(\mathrm{x})=\mathrm{PDR} \mathrm{x} \mathrm{k}-\mathrm{k} *[\mathrm{NO}+\mathrm{AD}+\mathrm{PD}]
$$

where,

NO = Normalized Overhead

$\mathrm{AD}=$ Average End to End Delay

$\mathrm{PD}=$ Number of Packet drop

PDR $=$ Packet Delivery Ratio

$\mathrm{k}=$ Proportionality constant used for the optimization of_tness function. Value of $\mathrm{k}$ lies between $0 \& 1$, i.e. $0 \leq \mathrm{k} \leq 1$.

\section{RESULTS}

\section{Simulation Parameters}

Simulations have been carried out in order to evaluate routing protocol. We focused our attention on the evaluation of network performance in terms of Drop Packet, Packet Delivery Ratio and All Delay, Average End to End Delay and Throughput of a mobile ad hoc network where a number of nodes are varying. Simulation environment to calculate the real time performance of the aforesaid quality of services parameters in Table 1.

\section{Simulation Scenarios}

Two simulation scenarios are used to simulate the effect of rushing attack and the effectiveness of prevention techniques in mobile ad hoc networks.

Table 1. Simulation setup.

\begin{tabular}{|l|l|}
\hline \multicolumn{1}{|c|}{ Number of Nodes } & \multicolumn{1}{c|}{$\mathbf{5 , 1 0 , 1 5 , 2 0 , 2 5}$} \\
\hline Topology & Static \\
\hline Simulation Time & $1000 \mathrm{Sec}$ \\
\hline MAC Layer & 802.11 \\
\hline Range & 200 meters \\
\hline Simulation Area & Simulation Area \\
\hline Routing Protocol & AODV \\
\hline Channel Type & Wireless Channel \\
\hline Traffic Model & Constant Bit Rate (CBR) \\
\hline Packet Size & 512 Bytes \\
\hline Interval & 1 Sec \\
\hline
\end{tabular}

1. Implementation of Traditional AODV Routing: In this simulation scenario, first of all we construct a mobile ad hoc network and configure it with the 
help of AODV routing protocol. Then an illegal node is set over MANET and gains the performance of AODV protocol with the help of trace file.

2. Implementation of AB-AODV Technique: In this simulation scenario a MANET is constructed and configures it with the help of AODV routing protocol after it an illegal node is constructed over MANET and obtained the performance of AB-AODV protocol. Finally simulate the effect of prevention techniques in the form of PDR, Throughput, Endto-End Delay, Drop packet and Lost Packet etc.

\section{PERFORMANCE PARAMETERS}

The following five performance parameters are used to study the protocols efficiency, adaptability, and scalability:

1. Throughput: It is defined as the total no. of number of packets received per second over simulation time.

2. Average End-to-End Delay: It is the average time delay incurred from the time when a data packet is sent from its source node until the data arrival at its destination node, divided by total number of data packets delivered at destination.

3. Packet Delivery Ratio: It is the ratio between the data packets delivered to the destination and those generated by Constant Bit Rate (CBR) sources. This evaluates the ability of the protocol to discover routes and its efficiency.

4. Normalized Overhead: This measures the protocol's internal efficiency. It is calculated as the total number of routing and control packets transmitted, divided by the number of data packets delivered successfully at destination.

5. Packet Drop: Total number of the packets that are dropped by the nodes in the path.

\section{PERFORMANCE ANALYSIS}

1. Throughput: In Figure 1, the red line shows throughput using $\mathrm{AB}-\mathrm{AODV}$ and the green line shows the performance of normal AODV. This fig shows the Comparison of Network Throughput with AODV and AB-AODV. The proposed algorithm improved good throughput compared to AODV with AB-AODV.

2. Drop Packet: Figure 2 shows comparison of network drop data packet with AODV and AB-AODV.
Drop data packet in presence of AODV is low and high after applied proposed technique.

3. Packet Delivery Ratio: In Figure 3 the number of nodes show on the $\mathrm{x}$-axis and packet delivery ratio show on the y-axis. This result shows the comparison of network packet delivery ratio with

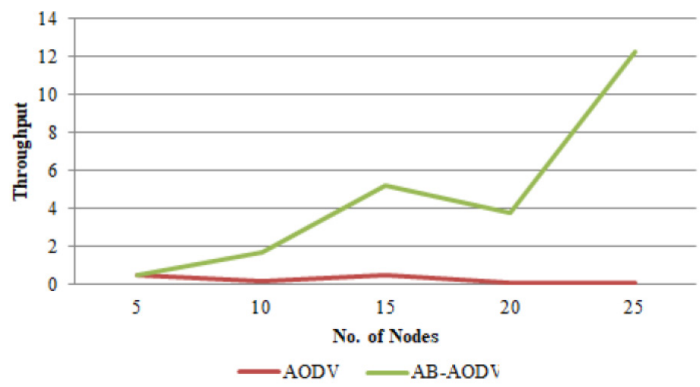

Figure 1. Comparison of Throughput.

\section{Drop Packet V/S No. of Packets}

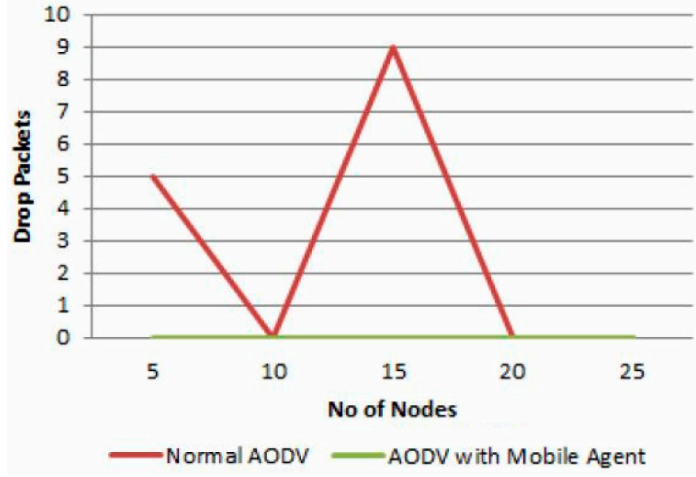

Figure 2. Comparison of Drop packets.

PDR V/S No. of Nodes

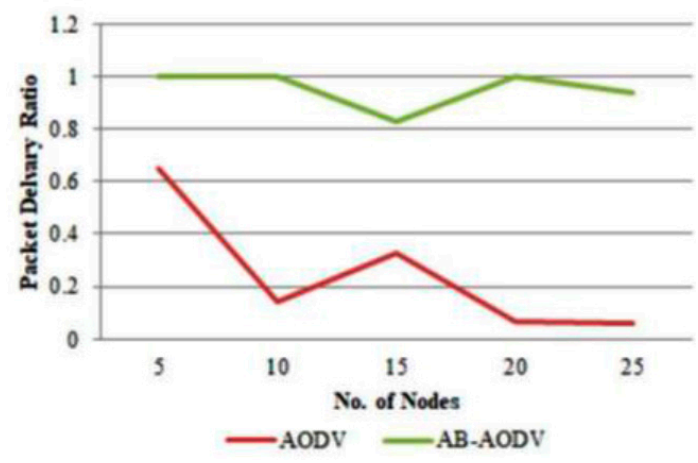

Figure 3. Comparison of Packet Delivery Ratio. 


\section{End to End Delay}

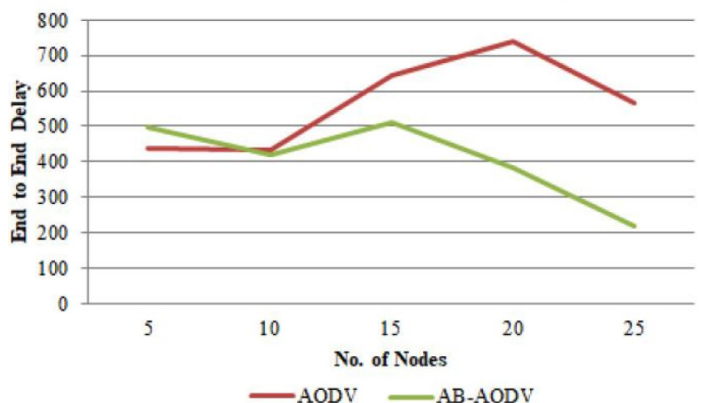

Figure 4. Comparison of End to End Delay.

AODV and AB-AODV technique. Red line shows the packet delivery ratio in presence of the AODV and the green line shows the packet delivery ratio after proposed technique. The graph shows that the packet delivery ratio is low in presence of AODV and improved after applying the technique.

\section{COMPARATIVE RESULTS}

1. Packet Delivery Ratio (PDR): The Table 2 shows the PDR for the AODV and AB-AODV. There is improvement in the Packet Delivery Ratio in the proposed technique. From the table it is visible that the PDR for AODV is less than the Packet Delivery Ratio for Proposed Method for nodes in the MANET.

2. End-To-End Delay (E2E): The Table 3 shows the E2E delay for the AODV and proposed technique. E2E Delay is decreased In Proposed Technique compared to AODV. The comparative End-To-End Delay graph is shown for the AODV and Proposed method. From Table 3 it is visible that the End-ToEnd Delay for Proposed Method is less than the Packet Delivery Ratio for AODV for nodes in the Mobile ad hoc network.

3. Throughput: The Table 4 shows the throughput for the AODV and proposed technique. Throughput

Table 2. Comparative Packet Delivery Ratio (PDR).

\begin{tabular}{|c|c|c|c|}
\hline $\mathbf{N}^{\mathbf{0}}$ of Node & PDR for AODV & PDR for Proposed Method & \% Improvement \\
\hline 5 & 0.68 & 1 & 0.32 \\
\hline 10 & 0.071 & 1 & 0.92 \\
\hline 15 & 0.73 & 0.9 & 0.17 \\
\hline 20 & 0.75 & 1 & 0.25 \\
\hline 25 & 0.79 & 0.9 & 0.11 \\
\hline
\end{tabular}

Table 3. Comparative End-To-End Delay (E2E).

\begin{tabular}{|c|c|c|c|}
\hline $\mathbf{N}^{\mathbf{0}}$ of Node & E2E for AODV & E2E for Proposed Method & \% Improvement \\
\hline 5 & 98 & 0.5 & -97.5 \\
\hline 10 & 97.3 & 0.4 & -96.9 \\
\hline 15 & 64.3 & 0.5 & -63.8 \\
\hline 20 & 87 & 0.4 & -86.6 \\
\hline 25 & 75 & 0.2 & -74.8 \\
\hline
\end{tabular}

Table 4. Comparative Throughput.

\begin{tabular}{|c|c|c|c|}
\hline $\mathbf{N}^{\mathbf{0}}$ of Node & Throughput for AODV & Throughput for Proposed Method & \% Improvement \\
\hline 5 & 0.07 & 0.5 & 0.43 \\
\hline 10 & 0.07 & 2 & 1.92 \\
\hline 15 & 0.15 & 5 & 4.85 \\
\hline 20 & 0.22 & 4 & 3.78 \\
\hline 25 & 0.22 & 12 & 11.8 \\
\hline
\end{tabular}


is increased in proposed techniques compared to AODV. The comparative analysis of the AODV and Proposed method represent that the throughput for AB-AODV is less than the throughput for AODV for nodes in the Mobile ad hoc network.

\section{CONCLUSION}

The improvement of routing protocol AODV with the help of mobile agents is proposed in this paper. Simulation is done under Network Simulator named NS-3 and observed results that AB-AODV is better than AODV in the aspects of throughput, delay and packet delivery ratio. We did analysis on 5, $10,15,20$ and 25 nodes in all the cases AB-AODV proved better than Traditional AODV.

\section{FUTURE WORK}

A new protocol should be automatic to adapt to the changes in topology and data trac. So, in future by this updating we can make AB-AODV more effective and responsive as a quick adaptation to conclude a number of mobile agents according to the changes in topology. In AB-AODV, to recognize the number of agents we have concluded manually the value of a number of agents. This makes AB-AODV more powerful and delay would also be minimized as manually configured work to evaluate mobile agents would be reduced.

\section{REFERENCES}

[1] M. Abdullah and H. Bakhsh. "Agent-based Dynamic Routing System for MANETs Agent-based Dynamic Routing System for MANETs". ICGST-CNIR Journal. Vol. 9, Issue 1. July, 2009.

[2] A. Bavalatti and A.V. Sutagundar. "Multi-agent based stable clustering in VANET". 2017 International Conference On Smart Technologies For Smart Nation (SmartTechCon), Bangalore, pp. 1033-1038. 2017. DOI: 10.1109/ SmartTech-Con.2017.8358527.

[3] H. Benkaouha, A. Abdelli, J. Ben-Othman, Y. Zaffoune and L. Mokdad. "Distributed implementation of a stable storage for MANET checkpointing protocols". 2016 International Wireless Communications and Mobile Computing Conference (IWCMC),
Paphos, pp. 672-677. 2016. DOI: 10.1109/ IWCMC.2016.7577137.

[4] V.S. Bhargavi, M. Seetha and S. Viswanadharaju. "A hybrid secure routing scheme for MANETS," 2016 International Conference on Emerging Trends in Engineering, Technology and Science (ICETETS), Pudukkottai, pp. 1-5. 2016. DOI: 10.1109/ICETETS.2016.7602991.

[5] B. Choudhury, S. Choudhury and A. Dutta. "A Multi-agent Based Optimized Service Replication Scheme for SOC in Mobile Ad Hoc Environment". 2015 IEEE/WIC/ACM International Conference on Web Intelligence and Intelligent Agent Technology (WI-IAT), Singapore, pp. 43-46. 2015. DOI: 10.1109/ WIIAT.2015.17.

[6] W. El-Hajj, G. Ben Brahim, H. Safa and M. Akkari. "MOLSR: Mobile-agent based optimized Link State Routing Protocol”. 2015 International Wireless Communications and Mobile Computing Conference (IWCMC), Dubrovnik, pp. 355-360. 2015. DOI: 10.1109/ IWCMC.2015.7289109.

[7] B. Fraser. "Radio-Frequency Emitter Localization Using a Swarm of Search Agents". 2018 28th International Telecommunication Networks and Appli-cations Conference (ITNAC), Sydney, SW, pp. 1-6. 2018. DOI: 10.1109/ATNAC.2018.8615450.

[8] I.T.A. Halim, H.M.A. Fahmy, A.M.B. El-Din and M.H. El-Shafey. "AgentBased Trusted On-Demand Routing Protocol for Mobile Ad Hoc Networks". 2010 Fourth International Conference on Network and System Security, Melbourne, VIC, pp. 255-262. 2010. DOI: 10.1109/ NSS.2010.53.

[9] K.L. Hassan, S. Bera and P. Bag. "Agent Based IDS Using RMBOPB Technique in MANET". Springer Nature, Singapore. Vol. 1, pp. 349-359. 2017. DOI: 10.1007/ 978-981-10-6427-228.

[10] O.I. Lysenko, A.V. Romanyuk, V.A. Romanyuk and Y.O. Sova. "The hierarchical model of intelligent control system between intelligent agents in sensor networks and manet". International Conference Radio Electronics \& Info Communications (UkrMiCo), Kiev, pp. 1-6. 2016. DOI: 10.1109/UkrMiCo.2016.7739627. 
[11] P.K. Mishra, R. Singh and V. Yadav. "Reliable Mobile Agent based system for suspicious MANET”. 2016 International Conference System Modeling \& Advancement in Research Trends (SMART), Moradabad, pp. 189-192. 2016. DOI: 10.1109/SYSMART. 2016.7894516.

[12] S.A. Mostafa, A.Y.C. Tang, M.H. Hassan, M.A. Jubair and S.H. Khaleefah. "A MultiAgent Ad Hoc On-Demand Distance Vector for Improving the Quality of Service in
MANETs". 2018 International Symposium on Agent, Multi-Agent Systems and Robotics (ISAMSR), Putrajaya, pp. 1-7. 2018. DOI: 10.1109/ISAMSR.2018.8540554.

[13] S.V. Kumari and B. Paramasivan. "Ant based Defense Mechanism for Selective Forwarding Attack in MANET". 2015 31st IEEE International Conference on Data EngineeringWorkshops, Seoul, pp. 92-97. 2015. DOI: 10.1109/ ICDEW.2015.7129553. 